\title{
RELAÇÃO DAS MULHERES COM O DINHEIRO PRECISA SER DESMITIFICADA
}

Coluna publicada em 7.3.2017: <https://www.conjur.com.br/2017-mar-07/ contas-vista-relacao-mulheres-dinheiro-desmistificada>

Estão enganados aqueles que pensam que esta coluna vai tratar de roupas, sapatos, cosméticos e idas a shopping centers. Uma falsa visão sobre a relação das mulheres com o dinheiro que precisa ser desmitificada. Nosso dinheiro - o dinheiro público -, como se poderá constatar, é muito bem aplicado se gerenciado pelas mulheres e se a elas for destinado.

Amanhã, dia 8 de março, se comemora o Dia Internacional da Mulher. Adotado pela ONU em 1977, foi uma data conquistada após mais de um século de lutas pela plena igualdade e de direitos que eram negados a elas.

O Estado brasileiro não fica alheio às importantes questões que envolvem as lutas por esses direitos que ainda não foram plenamente alcançados, e que ainda se fazem necessárias não só aqui como em muitos países do mundo.

Isso se pode observar pela existência de órgãos, políticas públicas e seus reflexos na atividade financeira do Estado brasileiro, materializada em programas orçamentários específicos e em recursos dispersos em dotaçôes diversas, evidenciando a especial atenção que elas merecidamente recebem e que o Direito Financeiro deve lhes dispensar.

É preciso enfatizar a importância de políticas públicas voltadas às mulheres. Talvez poucos saibam, mas já há algum tempo se evidencia que a pobreza não é um fenômeno independente do gênero. Diversos estudos e documentos internacionais mostram que as mulheres são expressiva maioria entre as populações pobres do planeta. Em 1995, o Relatório do Programa das Nações Unidas para o Desenvolvimento apontava que $70 \%$ dos pobres do mundo eram mulheres, que representa- 
vam também dois terços da população analfabeta. ${ }^{1}$ Passados mais de vinte anos, determinados grupos são mais afetados do que outros pelo multidimensional fenômeno da pobreza: nos países em desenvolvimento, os índices são maiores entre mães solteiras e mulheres idosas que vivem sozinhas, em comparação com homens de mesmas características. ${ }^{2}$ Em artigo seminal sobre o tema, a socióloga norte-americana Diane Pearce usou, em 1978, a expressão "feminização da pobreza" para caracterizar a expressividade da pauperização feminina naquele momento, a despeito de sua crescente participação na força de trabalho. ${ }^{3}$ Apesar das inúmeras discussões que o assunto tem levantado desde então entre os especialistas, diversas pesquisas corroboram resultados que indicam a propensão à pobreza de domicílios chefiados por mulheres nos países em desenvolvimento. ${ }^{4}$

As definições são variadas, e os debates a respeito da ocorrência do fenômeno com estas características no Brasil são muitos, o que não impede a conclusão de que as políticas públicas não devem ser neutras com relação à questão de gênero, pois "[a] existência de uma mesma proporção de homens e mulheres na pobreza não significa que ambos os grupos tenham as mesmas necessidades, que experimentem a pobreza da mesma maneira ou que tenham de seguir os mesmos caminhos para superar essa condição".

Segundo a ONU, a taxa de desemprego das mulheres é cerca de duas vezes a dos homens, e, na comparação de homens brancos com mulheres afrodescendentes, o percentual de 5,3\% aumenta para $12,5 \%$. A maioria das famílias brasileiras é chefiada por mulheres, que também se dedicam às tarefas domésticas. A violência contra as mulheres (feminicídio e estupros) dobrou entre 1980 e 2011, colocando o Brasil na $7^{a}$ posição dentre os países mais violentos. No Brasil uma mulher é assassinada a cada duas horas, na maioria dos casos por homens com os quais têm relações. O número de estupros foi superior a 50.000 em $2012 .{ }^{6}$

1 HAQ, Mahbul ul (Principal coordinator). Human Develop Report 1995. New York: Oxford University Press, 1995, p. iii.

2 The World's Women 2015 - Trends and Statistics, United Nations Statistics Div., ch. 8 <https:// unstats.un.org/unsd/gender/downloads/WorldsWomen2015_chapter8_t.pdf>, p. 179.

3 PEARCE, D. The feminization of poverty: women, work and welfare. The Urban and Social Change Review, vol. 11, n. 1, 1978, p. 28.

4 Como pode ser verificado no detalhado estudo de COSTA, J. S.; PINHEIRO, L.; MEDEIROS, M.; QUEIROZ, C. A face feminina da pobreza: sobrerrepresentação e feminização da pobreza no Brasil. Brasília: IPEA, 2005.

5 A face feminina..., p. 36.

6 Disponível em: <http://www.onumulheres.org.br/brasil/visao-geral/>. Acesso em: 4.3.2017. 
Há que se enfatizar também a complexidade para que seja possível criar e implementar políticas públicas voltadas às mulheres, uma vez que, assim como em outras áreas de atuação do Estado, não são específicas de uma esfera de governo, nem de um único setor da administração pública. As políticas que envolvem as mulheres são múltiplas e de variadas naturezas, tornando-as interfederativas, multissetoriais e transversais, envolvendo no mais das vezes uma complexa relação entre órgãos, poderes, instituiçõos e entes da federação.

Estas políticas públicas exigem a articulação de diferentes órgãos governamentais, como aqueles responsáveis pelos programas de educação e de saúde.

Por isso, o planejamento é fundamental, e a Secretaria Especial de Políticas para as Mulheres (SPM), ${ }^{7}$ no âmbito federal, instituiu em 2004 o Plano Nacional de Políticas para as Mulheres, ${ }^{8}$ com 199 ações, distribuídas em 26 prioridades, traçadas a partir de quatro linhas de atuação: autonomia, igualdade no mundo do trabalho e cidadania; educação inclusiva e não sexista; saúde das mulheres, direitos sexuais e direitos reprodutivos; e enfrentamento à violência contra as mulheres. Renovado e aperfeiçoado posteriormente em novas edições, o PNPM avança muito no enfrentamento de problemas relacionados às questôes de gênero, mas peca, tal como outros planos governamentais, pela sua pouca institucionalização, sequer sendo materializado em lei, o que fragiliza sua implementação e execução, especialmente por abranger políticas públicas interfederativas.

Daí por que convém analisar os programas orçamentários sob condução da Secretaria de Políticas para as Mulheres, previstos no sistema formal de planejamento orçamentário, incluídos nos planos plurianuais e nas leis orçamentárias, onde se constatam programas por ela gerenciados, como, no âmbito federal, o Programa de Promoção da Igualdade e Enfrentamento à Violência (Programa 2016, PPA 2016-2019), que congrega os objetivos de aplicação de recursos públicos para as políticas públicas voltadas às mulheres. É aí que se situam as metas de promoção de autonomia econômica, social, sexual e de garantia de direitos das mulheres (Objetivo 0931), visando, por exemplo, a capacitação de mulheres urbanas, rurais, do campo, da floresta e das águas para fortalecer sua participação no mundo do tra-

7 Que é relativamente recente, tendo sido criada em janeiro de 2003.

8 Inspirado no Programa ONU Mulheres, do qual participam vários países, inclusive o Brasil (ONU Mujeres - Informe Anual 2015-2016. New York: ONU, 2016. Disponível em: <http:// www2.unwomen.org/-/media/annual\%20report/attachments/sections/library/un-women-annual-report-2015-2016-es.pdf?vs=3039>).

9 I Plano Nacional de Políticas para as Mulheres. Brasília: Secretaria Especial de Políticas para as Mulheres, 2004. 
balho e o fomento à participação em empreendimentos econômicos solidários. A intersecção entre orçamento e políticas voltadas para as mulheres se torna mais evidente quando consideradas as iniciativas deste objetivo, as quais, se bem executadas, seriam poderoso instrumento de ação governamental para a melhoria de sua qualidade de vida e para a igualdade de renda e de bem-estar. Vejam-se as iniciativas de "implementação de ações para a promoção de autonomia econômica voltadas para as mulheres em situação de violência e para a garantia de direitos" (Iniciativa 05CM), as "ações de estímulo ao empreendedorismo das mulheres e de fortalecimento da organização e inclusão produtiva, em especial do segmento de mulheres catadoras e quilombolas" (Iniciativa $05 \mathrm{CN}$ ) e "as ações de apoio à aprovação e implementação do Projeto de Lei 4.857/2009, que trata da igualdade entre homens e mulheres no mundo do trabalho público e privado" (Iniciativa 05CP).

Além de se voltarem à integração econômica e à geração de renda, muitos objetivos visam ainda à participação social, à cidadania e à igualdade de um modo mais amplo. É o que se nota nos programas orçamentários que têm por objetivo promover a "a transversalidade intra e intergovernamental das políticas para as mulheres e de igualdade de gênero, observando as diretrizes do Plano Nacional de Políticas para as Mulheres" (Objetivo 0935); "fortalecer o processo de participação política, democrática e igualitária das mulheres, nas instâncias de poder e decisão, considerando sua diversidade e especificidades" (Objetivo 0934); e, finalmente, "ampliar a política nacional de enfrentamento de todas as formas de violência contra as mulheres, considerando sua diversidade e especificidades" (Objetivo 0998).

A formalização de políticas públicas nos planos e leis orçamentárias, no entanto, não é suficiente para garantir que sejam executadas, ou se executadas, que resultem em benefícios para as mulheres. É preciso que o controle interno, o controle externo e o controle social exerçam seu importante papel fiscalizatório, exigindo o cumprimento do planejamento, analisando os resultados e a eficiência da política planejada, o que nem sempre é preocupação do gestor público. Reavaliar as políticas públicas é uma obrigação, assim como implementá-las de forma mais eficiente.

E os gestores públicos não têm sido eficientes na implementação dessas políticas públicas, e, em razão dessa deficiência no planejamento e na execução das políticas, muito dinheiro é gasto em ações que acabam não resolvendo os problemas. Políticas mal planejadas geram gastos mal planejados, e nem todas chegam a ser implementadas, porque são contingenciadas, e na prática o que se verifica no Brasil é que a violência contra a mulher continua e aumenta a cada ano, a discriminação no ambiente de trabalho se mantém, persiste a falta de capacitação, de educação e de participação mais expressiva na política. 
A educação pública de qualidade, preferencialmente integral, inclusiva e igualitária, é a principal delas, porque formará cidadãos mais preparados, e as mulheres terão melhores condições de se tornar agentes, acessar empregos permanentes e qualificados, onde serão tratadas sem discriminação..$^{10}$ Da mesma forma, uma educação melhor e inclusiva propiciará às mulheres melhores condições e iniciativa para participar mais da política, seja nas açôes comunitárias, seja no poder legislativo ou no executivo, onde serão gestoras do dinheiro público, função que já estão desempenhando com eficiência na sua vida privada, apesar de tantos percalços.

A Finlândia é exemplo de eficiência na política pública de educação, o que resulta na proteção dos direitos da mulher também. ${ }^{11}$ Foi o primeiro país da Europa a conceder às mulheres, em 1906, o sufrágio universal. As finlandesas foram também as primeiras no mundo a obter a elegibilidade nas eleiçóes parlamentares, com plenos poderes políticos numa sociedade ainda patriarcal. ${ }^{12}$ Os países nórdicos figuram entre os três melhores índices em igualdade de gêneros. A lista foi divulgada pelo Fórum Mundial de Economia em 2015. A Islândia está em primeiro lugar, seguido da Finlândia e Noruega (empatadas) e depois a Suécia (a Dinamarca ocupa a $14^{\mathrm{a}}$ posição). Nesse ranking o Brasil está na $85^{\mathrm{a}}$ posição..$^{13}$

A situação brasileira está tão distante dos países nórdicos porque, ao contrário de lá, por aqui temos um país continental com acentuada desigualdade social, uma violência generalizada, uma das piores políticas de educação do mundo, e neste ano 2017, mais de 12 milhões de desempregados, muitos dos quais mulheres.

E as mulheres são reconhecidamente gestoras boas e responsáveis. Quando as mulheres conseguem ocupar cargos ou funções antes reservadas somente aos homens, elas têm um excelente aproveitamento e são eficientes tanto nos negócios como na economia ${ }^{14}$, e também na área pública.

Veja como pouco aparecem em escândalos de corrupção, má gestão e outros problemas dessa natureza; quase não estão presentes em casos rumorosos como a

10 <http://agenciabrasil.ebc.com.br/geral/noticia/2015-03/mulheres-precisam-ocupar-diferentes-areas-de-trabalho>

11 <http://noticias.universia.com.br/destaque/noticia/2016/10/24/1144860/conheca-4-paises-melhores-sistemas-educacionais.html\#> e <https://finland.fi/pt/vida-amp-sociedade/o-poder-da-simplicidade-do-sistema-educacional-finlandes/>

$12<$ http://www.finlandia.org.br/public/default.aspx? contentid=109006>

13 <http://www.brasileiraspelomundo.com/finlandia-igualdade-de-generos-na-sociedade-061628146>

14 SEN, Amartya. Desenvolvimento como liberdade. São Paulo: Companhia das Letras, 2010, p. $260-261$. 
"lava-jato", "mensalão" e outros. A própria legislação já reconheceu esta qualidade. $\mathrm{Na}$ Lei 11.977, que dispóe sobre o programa "Minha Casa Minha Vida-PMCMV", em seu art. 35, estabeleceu que os "contratos e registros efetivados no âmbito do PMCMV serão formalizados, preferencialmente, em nome da mulher”, e nos casos de separação, será registrado em nome da mulher. ${ }^{15}$

Instrumentos financeiros muito úteis, os fundos permitem a alocação direcionada e mais segura de recursos que viabilizam a implementação e execução das políticas públicas. É importante nesse sentido estar atento para aqueles que são voltados às questôes de gênero, como é o caso do Projeto de Lei 7371/2014, que cria o Fundo Nacional de Enfrentamento à Violência contra a Mulher, até hoje um grave problema no setor, e que necessita ser combatido, para o que fundos como esse têm especial relevância, sendo a aprovação desse projeto de lei uma medida importante para solucioná-lo. Há também destinação específica de recursos de fundos às políticas para as mulheres, como a prevista no FUNPEN (Fundo Penitenciário Nacional), que prevê recursos para manutenção de casas de abrigo destinadas a acolher vítimas de violência doméstica ${ }^{16}$ e para a implantação e manutenção de berçário, creche e seção destinada à gestante e à parturiente nos estabelecimentos penais. ${ }^{17}$

Veja-se que há muito o que fazer pelas mulheres, e o Direito Financeiro tem um papel importante a desempenhar.

Que amanhã as mulheres comemorem seu dia, e que este dia sirva de reflexão para os nossos gestores públicos darem a elas a atenção que merecem.

15 Lei 11.977, art. 35-A. Nas hipóteses de dissolução de união estável, separação ou divórcio, o título de propriedade do imóvel adquirido no âmbito do PMCMV, na constância do casamento ou da união estável, com subvenções oriundas de recursos do orçamento geral da União, do FAR e do FDS, será registrado em nome da mulher ou a ela transferido, independentemente do regime de bens aplicável, excetuados os casos que envolvam recursos do FGTS. (Incluído pela Lei 12.693, de 2012).

16 Lei Complementar 79/1994, art. 3º, XIV, com redação dada pela Lei Complementar 119/2005.

17 Lei Complementar 79/1994, art. 3º, XV, com redação dada pela Lei Complementar 153/2015. 